7. Rudin JE, Geldt VG, Alecseev EB. Prolapse of urethral mucosa in white female children: Experience with 58 cases. J Pediatr Surg. 1997;32:423-5.

8. Falandry L. Urethral prolapse in young black girls. Report of 12 cases. Prog Urol. 1996;6:392-7.

9. Golomb J, Merimsky E, Braf Z. Strangulated prolapse of the urethra in the elderly female. Int J Gynaecol Obstet. 1985; 23:61-3.

10. Nakao M, Mishina T, Kobayashi T, Maegawi M, Nakagawa S, Imashuku S. A case of rhabdomyosarcoma of the bladder in a child with urethral prolapse. Hinyokika Kiyo. 1983;29: 233-238.

11. Pascual D, Trívez MA, García MA, García de Jalón A, Carela J, Rioja LA. Prolapso uretral tras esfuerzo físico. Corrección quirúrgica. Actas Urol Esp. 2002;26:699-702.
12. Soares MJ, Covita A, Neves T, Monteiro P, Canhoto A, Nogueira R, et al. Prolapso uretral encarcerado. A propósito de un caso. Arch Esp Urol. 2008;61:922-4.

13. Devine PC, Kessel HC. Surgical correction of urethral prolapse. J Urol. 1980;123:856-7.

J.D. Jiménez Parra*, J.L. Cebrián Lostal, F. Lozano Uruñuela y S. Alvarez Bandrés

Servicio de Urología, Hospital Virgen del Camino, Pamplona, España

*Autor para correspondencia.

Correo electrónico: jdjimenez@hotmail.es (J.D. Jiménez Parra).

\title{
Una técnica sencilla para el implante testicular con adecuada elección del tamaño: reporte de un caso
}

\section{A simple technique for testicular implant insertion and size election: A case report}

\section{Sr. Director:}

La falta de un testículo no sólo puede ocasionar un problema psicológico, sino también físico o estético; es por eso por lo que los pacientes cada vez demandan procedimientos con mejores resultados estéticos, que no solo consisten en reparar la falta, sino en esconder en lo posible las evidencias de la cirugía ${ }^{1}$.

En un estudio sobre pacientes a los que se les practicó una orquidectomía por cáncer testicular, el 27\% de los encuestados que portaban una prótesis testicular estaba disconforme con su posicionamiento, el $37 \%$ no estaba satisfecho con el tamaño y a un tercio de los pacientes no se les ofreció la posibilidad de prótesis ${ }^{2}$.

Presentamos una técnica sencilla para el implante testicular con adecuada elección del tamaño y buen resultado estético así como satisfacción del paciente.

Se presenta el caso de un paciente de 27 años de edad con orquidectomía derecha previa, realizada en su adolescencia debido a la falta de descenso del testículo. Después de recibir antibióticos, se marcó una línea media escrotal así como una incisión supraescrotal. La incisión se infiltró con bupivacaína 0,25 con adrenalina 1:200.000. Se realizó una incisión de $2 \mathrm{~cm}$ supraescrotal y se accedió al escroto mediante disección roma. Para la correcta colocación y elección del tamaño de la prótesis se introdujo una sonda de Foley $16 \mathrm{~F}$ en el escroto (fig. 1). Se fue rellenando el balón de la sonda hasta $32 \mathrm{ml}$, momento en el que el tamaño era similar al testículo contralateral. Una vez que estuvo bien emplazada la sonda y medido el tamaño de la prótesis, se procedió a la expansión tisular inmediata del escroto, rellenando el balón hasta $40 \mathrm{ml}$.
Se sumergió la prótesis en cefazolina y se retiró la sonda después de deshinchar el balón. Los cirujanos procedieron al cambio de guantes y lavado de estos con cefazolina, así como a pincelar la incisión con povidona yodada. Se insertó la prótesis, que fue colocada y fijada a la parte baja del escroto

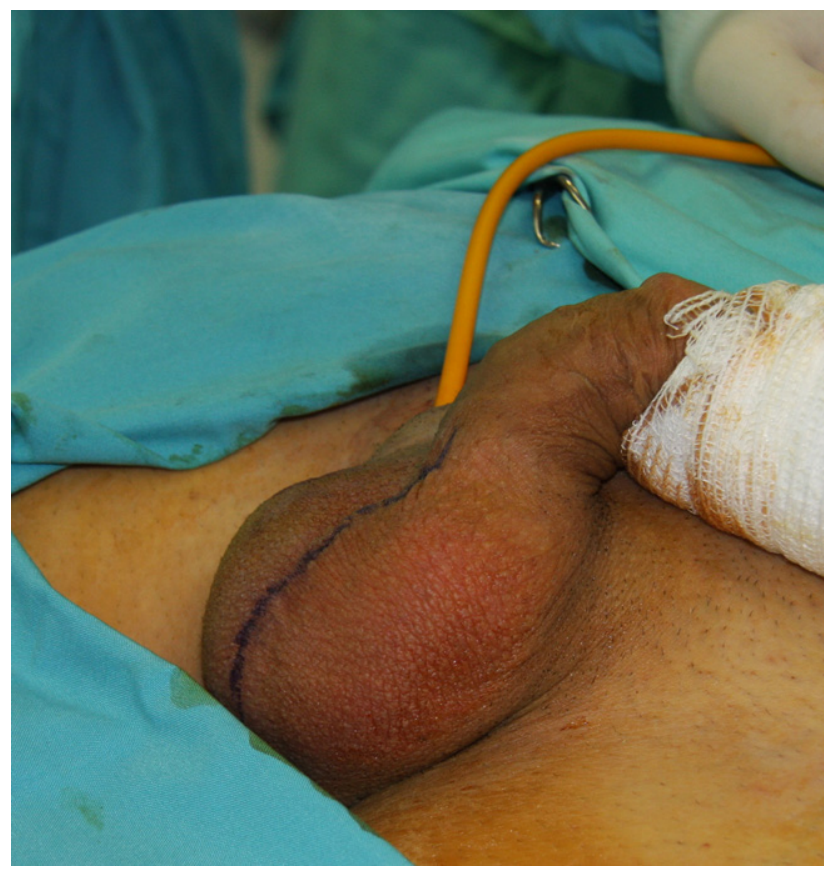

Figura 1 - La inserción en el escroto de un catéter de Foley 16F fue usada para el correcto emplazamiento y medición del tamaño de la prótesis. 


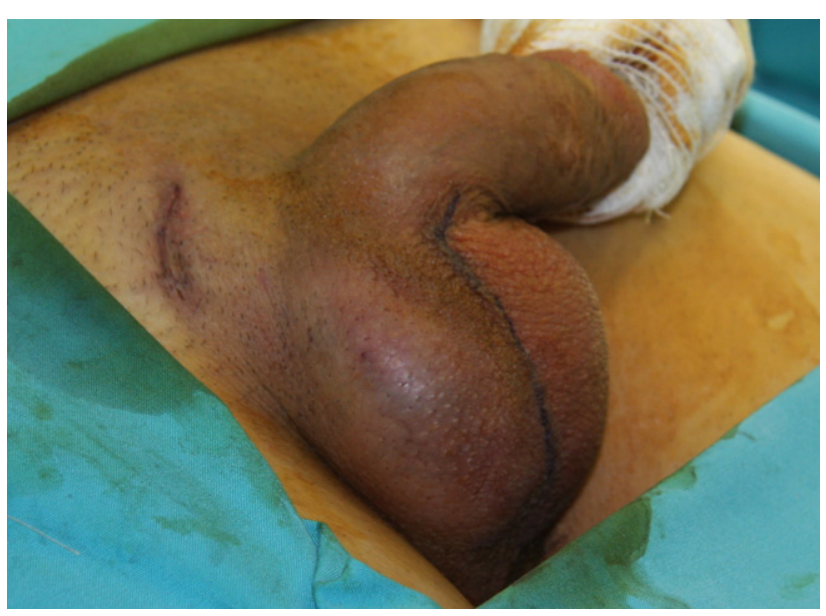

Figura 2 - Resultado final. Correcto emplazamiento así como adecuado tamaño y simetría.

mediante eversión digital de este y exposición a través de la incisión. Se colocó una prótesis de $4,5 \times 3 \times 2 \mathrm{~cm}$. Se suturó la incisión con sutura reabsorbible $4 / 0$ para el subcutáneo y puntos sueltos de nylon 5/0 para la piel. Fijando la prótesis con esta técnica, aseguramos un correcto emplazamiento y prevenimos una posible elevación a la par que mejoramos el resultado final (fig. 2).

La utilización de esta técnica, asociando la incisión supraescrotal y la utilización del catéter de Foley para una correcta estimación del tamaño, nos permite asegurar un correcto emplazamiento así como un adecuado tamaño y simetría de la prótesis. El contacto entre la cicatriz y la prótesis puede resultar en contaminación de la prótesis; este contacto suele ocurrir ya sea con una incisión inguinal o escrotal. Los resultados estéticos de estos abordajes tampoco suelen ser óptimos. Sin embargo, el abordaje supraescrotal tiene la ventaja de quedar oculto por el vello púbico así como de dejar el escroto libre de cicatrices. La fijación de la prótesis al escroto previene su elevación y asegura un correcto emplazamiento. El uso del catéter de Foley proporciona un sencillo y práctico sistema de medida que asegura la correcta elección de tamaño de la prótesis, repercutiendo todo ello en una mayor satisfacción del paciente.

B I B L I O G R A F Í A

1. Winkler H, Kleinmann N, Raviv G, Chertin B, Ramon J, Mor Y. Testicular prosthesis insertion following testicular loss or atrophy during early childhood-technical aspects and evaluation of patient satisfaction. J Pediatr Urol. 2007;3:461-5.

2. Adshead J, Khoubehi B, Wood J, Rustin J. Testicular implants and patient satisfaction: A quiestionnaire-based study of men after orchidectomy for testicular cancer. BJU Int. 2001;88: 559-62.

C. Casale*, J. Buendía-Pérez, J. Botellé-Del Hierro y

B. Hontanilla-Calatayud

Departamento de Cirugía Plástica, Clínica Universidad de Navarra, Pamplona, España

*Autor para correspondencia.

Correo electrónico: drcasale@hotmail.es (C. Casale).

\section{Tumor fibroso solitario renal (reporte de caso)}

\section{Solitary fibrous tumor of the kidney (a case report)}

\section{Sr. Director:}

Los tumores fibrosos solitarios (TFS) son tumores mesenquimales de probable tipo (mio)fibroblástico que muestran un característico patrón vascular ramificado hemangiopericitoide que usualmente se desarrollan en la pleura.

Hasta un $30 \%$ de los casos han sido reportados en partes blandas y órganos parenquimales. Pocos son los casos descritos en el riñón ${ }^{1-8}$.

Se trata de una paciente de 39 años, con disuria y polaquiuria, a la que se le diagnosticó infección del tracto urinario. La TAC reportó una lesión sólida, hipodensa, captadora de contraste de forma heterogénea, de $2,3 \mathrm{~cm}$ de diámetro mayor y que condicionaba infiltración del sistema colector adyacente. Se realizó nefrectomía radical izquierda y linfadenectomia paraórtica.

A nivel de la pelvis renal se identificó una neoformación nodular, sólida, pardo clara, de bordes expansivos, de $2,5 \mathrm{~cm}$ de diámetro mayor. El resto del riñón no tenía alteraciones significativas.

Microscópicamente (fig. 1), el tumor era fusocelular, de celularidad moderada, con bandas hialinas de colágeno, atipia nuclear ausente e índice mitótico bajo, el parénquima renal estaba focalmente comprometido. El perfil inmunohistoquímico fue CD34(+) (fig. 2), Bcl-2(+), CD99(+), S-100(-), desmina(-), actina(-), HMB-45(-), CD117(-) e índice proliferativo (Ki67) bajo: del 2-3\%.

Los TFS son neoplasias mesenquimales reportadas en partes blandas y diversos órganos. Son neoplasias primitivas mesen- 